\title{
RESPIRATORY CAPACITY FOLLOWING TUBAL INSUFFLATION
}

\author{
P. Gilroy Bevan, Ch.M., F.R.C.S. \\ Consultant Surgeon, Dudley Road Hospital, Birmingham, 18: formerly Lecturer in Surgery \\ Surgery Professorial Unit, Queen Elizabeth Hospital, Birmingham, 5
}

Insufflation of the Fallopian tubes with gases is used as a diagnostic and therapeutic measure in cases of infertility. ${ }^{7}$ If the tubes are, or become patent the gas enters the peritoneal cavity.

This paper reports the results of respiratory capacity measurements in a series of patients undergoing insufflation. There were two aims in this study:

(I) To ascertain whether a simple test of respiratory capacity would be sufficient diagnostic measure of a successful tubal insufflation.

(2) To measure if small amounts of air entering the peritoneal cavity alter respiratory capacity. This has an application to abdominal surgery.

Thirty-five patients were studied in this series. All were fit and healthy young women attending a Fertility Clinic. Their age range was 19 to $3^{6 .}$

\section{Method}

One tubal insufflation was carried out on each patient, and this was done without general anaesthesia. With the patient in the lithotomy position, the cervix was dilated with Hegar's dilators, and the insufflating cannula was introduced into the body of the uterus. The flowmeter was set at 75 c.c./minute, and gaseous carbon dixoide was insufflated.

If the tubes were found to be patent, varying amounts of gas were introduced according to the patient's reaction. A kymographic record of each insufflation was made by means of a circular chart on a revolving drum: if the tubes appeared blocked, this record enabled a distinction to be made between tubal spasm or occlusion. ${ }^{7}$ In all cases where the tubes appeared blocked the patient was given amyl nitrite by inhalation to relieve tubal and uterine spasm, to ascertain if this was the cause of the obstruction.

The following criteria were used to indicate tubal patency:

(I) Gas passing through the tubes as indicated by the kymographic record. This occurred at pressures varying from 60 to $100 \mathrm{~mm}$. $\mathrm{Hg}$. High pressures of $15^{\circ}$ to $200 \mathrm{~mm}$. $\mathrm{Hg}$. indicated tubal occlusion.

(2) Typical bubbling sounds heard by auscultation of the lower abdomen.

(3) Pain in the shoulders or neck felt by the patient 5 to 15 minutes after sitting upright at the end of the insufflation.

One of the simplest measurements of respiratory capacity is the forced expiratory volume measured for one second (F.E.V.1) as described by Gandevia and Hugh-Jones. ${ }^{2}$ A close correlation has been found between the forced expiratory volume and the maximum breathing capacity.4, 8 Gandevia and Prime $^{3}$ concluded that, from the practical clinical point of view, measurement of the F.E.V. is a sensitive indication of breathing capacity changes.

The forced expiratory volume (I second) was estimated on all the patients before the insufflation (when they were instructed how to do the test), again immediately after the insufflation, and finally half an hour later when any pain or shock had worn off. Thus three sets of readings were taken in each patient, and each reading was the maximum of three F.E.V.'s.

All the F.E.V. measurements were made by means of a sensitive spirometer acting on a fast moving kymograph, as described by Bernstein et al. ${ }^{1}$

\section{Groups}

The patients were divided into three groups as follows:

A (22 cases):

Patients in whom the tubes were patent, and gas entered the peritoneal cavity, as witnessed by pain in the shoulder or neck, auscultation and the kymographic record.

B (4 cases):

Those in whom the tracing and auscultation revealed gas passing through the tubes into the 
peritoneal cavity, but who experienced no neck or shoulder pain; presumably the gas entered the pelvic part of the peritoneal cavity, but did not pass up into the upper abdominal cavity, due to the disposition of the viscera or adhesions, etc. C (9 cases):

Those with blocked tubes as shown by a very high pressure on the chart, no sounds of auscultation and absence of pain.

Group $\mathrm{C}$ acted as a control group, and revealed reduction in respiratory capacity due to factors other than the entrance of gas into the peritoneal cavity, such as pain, shock, or nervous inhibition.

\section{Results}

The results of the three sets of F.E.V.1 readings for all 35 patients are given in Table $\mathbf{r}$, together with the amounts of gas insufflated in the first two groups. This amount was calculated from the flowmeter rate and the duration of the insufflation; the kymographic chart revealed the time period over which the tubes were transmitting the gas. To check these factors, all the insufflations were witnessed personally.

For changes in the F.E.V.1 to be significant, values of $6 \%$ or over were considered necessary, as changes of lesser degree than this could well have been due to the variability of the technique. The initial F.E.V. reading was compared with the higher of the second or third readings, i.e. the maximum breathing capacity of which the patient was capable following insufflation.

In group A, 9 out of 22 cases showed significant reduction in F.E.V.$_{1}$ following tubal insufflation. Where 100 c.c. of gas or more was introduced, five out of nine showed reduced breathing capacity; with less than 100 c.c., four out of 13 .

In group $B$, three out of four showed significant F.E.V. reduction, and in group $C$ only three out of nine. Taking groups $A$ and $B$ together, the F.E.V. was reduced in 12 out of $26(46 \%)$ as compared with $33 \%$ in the control group C.

The general conclusion is that tubal insufflation of the amounts used in this series caused some slight reduction in breathing capacity. Where 100 c.c. or more was used, the reduction in F.E.V.1 was definite as compared with the controls. In the cases in which a smaller volume was used there was no greater reduction than in the control group.

\section{Shoulder Pain}

All the cases in group A experienced pain in the shoulders or neck on sitting up after the insufflation. Usually the pain was pleuritic in nature, suggesting relationship to the diaphragm, as might result from stretching. The pain usually lasted about ten minutes and had disappeared in all cases
Table I

F.E.V. Recordings in 35 Patients UndergOING TUBAL INSUFFlation

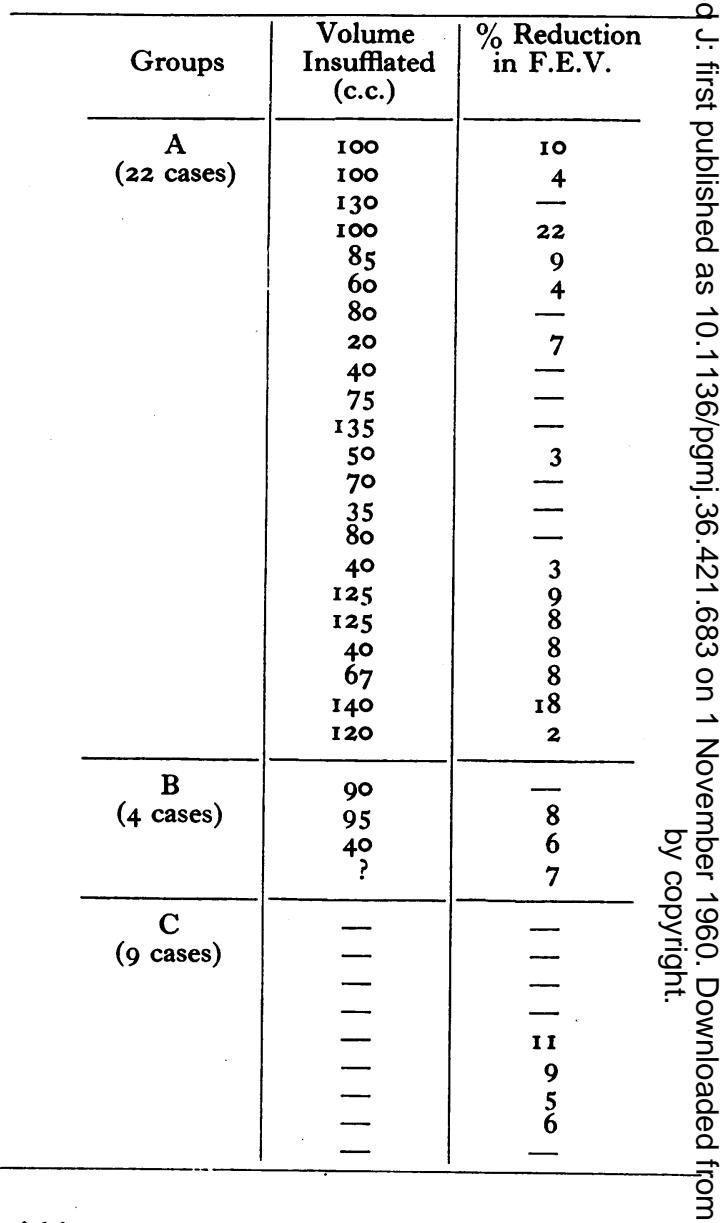

within 20 minutes of the insufflation. The dis? tribution of the pain in the 22 cases was as follows?

$\begin{array}{lllll}\text { In both shoulders } & \ldots & \ldots & \ldots & 8\end{array}$

Right shoulder only. . $\quad$. . $\quad \ldots \quad 5$

Left shoulder only .. $\quad \ldots \quad \ldots 6$. 6

At the base of the neck in the mid-

line posteriorly .. $\quad . . \quad \ldots \quad 3$

There seems to be no distinct pattern of distribution, and the air would appear to follow no definite route as it passes from the pelvis up undep the diaphragm.

\section{Speed of Absorption}

Carbon dioxide was used throughout fo insufflation. Its absorption from the peritoneats cavity is much more rapid than that of air. Carbon dioxide is 20 times more soluble than oxygen aq body temperature, ${ }^{5}$ and therefore diffuses and is absorbed more quickly. Lumsden and Truelove claimed that a litre of carbon dioxide can be 


\section{Hospital Infection}

Causes and Prevention

\begin{tabular}{lcc} 
R. E. O. WILLIAMS & R. BLOWERS & 12 illustrations \\
M.D., M.R.C.P. & M.D. & (1960) 35s. net \\
L. P. GARROD & R. A. SHOOTER & \\
M.D., F.R.C.P. & \multicolumn{1}{c}{ M.D. } &
\end{tabular}

Fluid Balance in Obstetrics

A Critical Review

$x+170 p p$.

PHILIP RHODES

M.B., F.R.C.S.(Eng.), M.R.C.O.G.

5 illustrations

(1960) 25s. net

A Practice of Anaesthesia

W. D. WYLIE

M.B.(Cantab.), M.R.C.P.(Lond.), F.F.A.R.C.S.

$x v i+1056 p p$.

327 illustrations

1 colour plate

H. C. CHURCHILL-DAVIDSON

M.D.(Cantab.), F.F.A.R.C.S.

(1960) 105s. net

\section{Practical Obstetric Problems \\ IAN DONALD \\ M.B.E., M.D.(Lond.), F.R.F.P.S.(Glas.), F.R.C.U.G.}

$x v i+712 p p$.

139 illustrations

(2nd. edit. 1959)

55s. net

absorbed by the peritoneum in 30 to 40 minutes. Absorption at such a rapid rate would mean that carbon dioxide would reduce the F.E.V. by less than the same volume of air, especially at the halfhourly reading. To make sure of this point, $\mathrm{X}$-rays of the subdiaphragmatic region, both posteroanterior and lateral views, were carried out in three patients in this series. The $\mathrm{X}$-rays were taken two to three hours after the insufflation, and in each case there was a thin layer of air under the diaphragm. This would confirm the findings of Landes and Ransom ${ }^{5}$ that carbon dioxide takes some hours to absorb. For the purposes of this investigation, therefore, carbon dioxide would have the same effect as an equivalent volume of air, as the F.E.V. estimations were all made within 30 minutes of insufflation.

Of the patients who were X-rayed, one showed a small left-sided pneumoperitoneum and developed shoulder pain on the left after insufflation; the second developed right shoulder pain and showed a small pneumoperitoneum on the right: the-third patient developed bilateral shoulder pain and showed a thin layer under both sides of the diaphragm. This confirmed that only a small amount of air under the diaphragm leads to pain under the corresponding shoulder.

\section{Conclusion}

The results of this study show that pneumoperitoneum in small amounts has very little effect on respiratory capacity when introduced by tubal insufflation. Any test of respiratory function would not be of value as a measurement of the success of tubal insufflation. Surgical patients left with a small amount of pneumoperitoneum following laparotomy probably suffer from negligible reduction of respiratory capacity as a result.

\section{Acknowledgements}

My grateful thanks are due to Miss M. Shotton for allowing me to study the patients at her Fertility Clinic. The spirometer was made in the Surgical Research Laboratory Workshop, the Queen Elizabeth Hospital, Birmingham, by Mr. H. A. Crisp.

\section{REFERENCES}

I. BERNSTEIN, L., D'SILVA, J. L., and MENDEL, D. (I952), Thorax, 7,255 .

2. GANDEVIA, B. H., and HUGH-JONES, P. (1957), Ibid. $12,290$.

3. GANDEVIA, B. H., and PRIME, F. J. (1957), Ibid., 12, 358.

4. KENNEDY, M. C. S. (1953), Ibid., 8, 73 .

5. LANDES, R. R., and RANSOM, C. L. (1957), Surg. Gynec. Obstet., ro5, 268.

6. LUMSDEN, K., and TRUELOVE, S. C. (1957), Brit. F. Radiol.,

7. SHÄ, ${ }^{316 .}$. (1943), 'Textbook of Gynaecology.' London: Churchill.

8. TIFFENEAU, R., BOUSSER, J., and DRUTEL, P. (1949), Paris med., r37, 543. 